\title{
Introduction: Just Getting Started
}

\author{
K. W. M. FULFORD
}

Ten years ago the Royal Institute of Philosophy marked the establishment of the Society for Applied Philosophy with a series of public lectures, published in an earlier book in this series, under the title Philosophy and Practice (Griffiths, 1985). Looking back it is hard to believe this was only ten years ago. Applied philosophy still has its critics. But it is now so pervasive, so much the norm, that it seems to have been with us always. Law, medicine, education, nursing, the environment, politics, economics . . . almost it seems, no subject is quite respectable nowadays without its philosophy and its philosophical exponents.

Psychiatry is a relative newcomer to the applied philosophy party (Fulford, p. 5, this volume). There are evident historical reasons for this: as Jeremy Holmes (p. 41) notes, psychiatry has gained respectability as a medical discipline by identifying itself with empiricism. But now that it has arrived, psychiatry brings with it a new vision of what the party is all about.

The rise of applied philosophy is generally portrayed as a reaction to the supposed aridity of the analytical philosophy of the post-war period. Preoccupied as it was with questions of meaning, philosophy appeared to have lost its connections with questions of substance. Bernard Williams (1985) captures a poignant image of the impotence of the professor's arguments when the mob breaks down the door and tramples his glasses. Against this background, then, the ethical issues generated by the explosive growth of technological medicine were a life-line to philosophers. And so it was that medicine, as Stephen Toulmin (1982) first put it, 'saved the life of ethics'.

The conception of applied philosophy to which this story leads has had important results: in health care, and in other practical disciplines, there is a new awareness of the ethical aspects of practice; and in philosophy itself there has been a renewed interest in the real world, in case-centred reasoning, in virtue-ethics, and, in the philosophy of mind, attention to the findings of empirical psychology. But for all this it is an essentially negative conception, emphasizing substance at the expense of meaning, practice at the expense of theory, ethics itself at the expense of metaphysics. Indeed in medicine, bioethics is essentially bolted on, a prosthetic addi- 
tion, important in practice perhaps, but peripheral to the biotechnology by which most doctors still take their subject to be defined.

Psychiatry has shared in the returns from applied philosophy, so conceived. Indeed to the extent that these have been mainly ethical returns, it has extended and enriched them. There is no shortage of real cases in this book. There is no shortage of real ethical dilemmas. Some of the topics would certainly be familiar to bioethicists-dangerousness (Walker, p. 179), consent (Devereux, p. 191), and autonomy (Holmes, p. 41). But bioethics, even when proceeding by case-centred reasoning, would standardly be concerned mainly with the applications of a relatively narrow range of broadly liberal-utilitarian values to issues arising in treatment. Whereas, applied to psychiatry, philosophy finds itself concerned also with morals (Taylor, p. 145; Wilkes, p. 115) and aesthetics (Storr, p. 213), tackling questions of diagnosis as well as treatment (Quinton, p. 197), meeting conceptual problems, problems of meaning, head on (Fulford, p. 5; Robinson, p. 159), and being drawn through these irresistibly into many of the deep problems of general metaphysics-the mind-brain problem (Papineau, p. 73); epistemology (Shotter, p. 55); rationality (Wilkes, p. 115); meaning and cause (Holmes, p. 41); the nature of consciousness (Boden, p. 103); and, linking several of the articles that follow, personal identity (Harré, p. 25; Binns, p. 83; Hope, p. 131; Boden, p. 103; and Taylor, p. 145).

Philosophical theory and medical practice come together in psychiatry at a number of levels. There may be direct transfers of skills and ideas between them. Thus Papineau (p. 73) shows the relevance of recent work in the philosophy of mind to the debate about the validity of mental illness; Binns (p. 83), on the other hand, draws conclusions about the nature of personal identity from the remarkable disturbances of volition found in schizophrenia. There may be a convergence of themes. The second cognitive revolution, described by Harré (p. 25), shares with family and group dynamics, a conception of agency as located not within the individual but in shared discursive practices. There may be a deeper sharing of models. Psychiatry, in showing that medicine has been too much influenced by the model of natural science (Fulford, p. 5), points also to the possibility, suggested by Wittgenstein (Lee, 1980), that philosophy, too, may have been too much influenced by this model.

There are many dangers here, of false analogy (of a new 'psychiatrism' in place of earlier psychologisms), of conflation (philosophy and psychotherapy really are different), of a slide from philosophy to philosophising (from rigorous metaphysics to meta- 
physical system building). These dangers are the more real for the continuing needs of practitioners to find 'answers', and of philosophers to make themselves 'useful'.

Analytical philosophy, among other possible approaches, avoids these dangers. In confining itself to conceptual difficulties it tackles local problems with the modest objective of improved understanding. Linked with a discipline like psychiatry this is far from being practically empty. As the range of contributions to this book shows, psychiatry is beset with conceptual (as well as empirical) problems in all aspects of diagnosis, treatment and research. It was indeed the richness of this range of problems which J. L. Austinthe personal target of much of the attack on post-war analytical philosophy-had in mind when he pointed philosophers to psychiatry over thirty years ago (Austin, 1956/7). Here, then, in psychiatry, analytical and applied philosophy are one and the same! Work in so limited an area, as Austin was the first to emphasise, can never be the last word in philosophy. But it may be the first word. It may be one way of getting started with certain kinds of philosophical problems (Warnock, 1989, ch. 1). In psychiatry, we are just getting started. 